\title{
Endoscopic Endonasal Approaches for Benign Tumors Involving the Skull Base
}

\author{
Aaron R. Cutler · Kian Karimi · Pablo Villanueva • \\ Garni Barkhoudarian • Chester F. Griffiths • \\ Daniel F. Kelly
}

Published online: 14 August 2013

(C) Springer Science+Business Media New York 2013

\begin{abstract}
With continued refinements in endoscopic image quality, instrumentation, surgical navigation, skull base closure techniques, anatomical understanding, and advanced neurosurgical and otolaryngological training, the endonasal endoscopic approach has become a well-accepted and widely utilized technique for the resection of most benign midline ventral skull base tumors. While pituitary adenomas and Rathke's cleft cysts constitute the most common lesions removed via this route, increasing experience has led to its broader utilization for more complex lesions, including craniopharyngiomas, midline meningiomas, and schwannomas. In this article, we review the recent literature published on this topic with an emphasis
\end{abstract}

A. R. Cutler · G. Barkhoudarian · C. F. Griffiths ·

D. F. Kelly $(\bowtie)$

Brain Tumor Center and Pituitary Disorders Program,

John Wayne Cancer Institute at Saint John's Health Center, 2200 Santa Monica Blvd, Santa Monica, CA 90404, USA e-mail: kellyd@jwci.org

A. R. Cutler

e-mail: cutlera@jwci.org

G. Barkhoudarian

e-mail: barkhoudariang@jwci.org

C. F. Griffiths

e-mail: chestermd@aol.com

K. Karimi · C. F. Griffiths

Pacific Eye \& Ear Specialists, 11645 Wilshire Blvd,

Los Angeles, CA 90025, USA

e-mail: kiankarimi@gmail.com

P. Villanueva

Department of Neurosurgery, Hospital Clínico,

Pontificia Universidad Católica de Chile,

Marcoleta 350, Santiago, Chile

e-mail: pablovillanueva@neurocirugiauc.cl on the most interesting and important new results and discoveries for each type of benign skull base tumor.

Keywords Endoscopic techniques - Skull base surgery Pituitary adenoma $\cdot$ Craniopharyngioma $\cdot$ Meningioma

\section{Introduction}

The rising interest in endoscopic transsphenoidal surgery during the 1990s and early twenty-first century has resulted in many if not most neurosurgeons transitioning first from a traditional microscopic to an endoscopic-assisted and eventually to a fully endoscopic approach. Jho and Carrau [28] and Cappabianca et al. [5] became the first to describe the endonasal endoscopic technique for standard sellar lesions. Over the years, in addition to pituitary adenomas and Rathke's Cleft Cysts (RCCs), the superior panoramic view and enlarged working angle offered by the endoscope has resulted in it being increasingly utilized for more complex lesions beyond the confines of the sella [45, 58]. Among other things, this development has also reintroduced the collaboration between neurosurgeons and the otolaryngologist-head and neck surgeons. Over the years, this collaboration has facilitated a further reach of these extended or expanded approaches to the entirety of the midline skull base, offering an increasingly favored option over traditional lateral and frontolateral skull base approaches. These include the transcribiform [29, 33] and transplanar approaches to the anterior cranial fossa and suprasellar region $[6,20,61]$, the transclival approach for infrasellar and pre-pontine lesions [30, 34], and the transC1/trans-odontoid approach to the foramen magnum [32]. Endoscopic approaches to more paramedian and lateral skull base regions including the infratemporal fossa, 
petrous apex, Meckel's cave, and ventrolateral cervicomedullary junction have also been recently described [35, $36,49]$. The following review covers the most impactful/ relevant articles published in late 2011, 2012, and early 2013 with an emphasis on technical details and surgical nuances of the endonasal endoscopic approach, and on the utilization of this approach in the surgical management of pituitary adenomas, craniopharyngiomas, meningiomas, and schwannomas.

\section{Endonasal Approach and Skull Base Reconstruction}

The approach to the various regions of the ventral skull base has become one of the main responsibilities of the rhinological surgeon in standard endonasal endoscopic procedures. Reconstruction and prevention of cerebrospinal fluid (CSF) leaks has been a collaborative endeavor between the two surgical specialties. Entire fellowships are now dedicated to the craft of "skull base surgery" for the otolaryngologist-head and neck surgeon, emphasizing the importance of this emerging field.

Currently, most endonasal endoscopic approaches involve a bi-nostril, two-surgeon technique. This typically includes wide bilateral sphenoidotomies with posterior ethmoidectomies and a posterior septectomy to create one common "optical cavity" for a coordinated, high-resolution removal of anterior fossa, sellar, suprasellar, or clival tumors. One of the early limitations of expanding the indications of endonasal skull base surgery was reconstruction, as CSF leaks became the most common postoperative complication of such approaches [23]. The description and utilization of a posterior-based vascular pedicled nasoseptal flap by Hadad and Bassagaisteguy in 2006, however, has significantly reduced the incidence of post-operative CSF leaks in extended approaches to the supra- and parasellar regions [23, 37]. Initially, it was necessary to raise a full nasoseptal flap at the start of each endonasal endoscopic procedure in order to have it available for reconstruction should a large CSF leak be encountered. Otherwise, there was a risk of both vascular pedicles potentially being sacrificed either intentionally or inadvertently during the standard posterior septectomy and sphenoidotomy [1]. In order to the circumvent this problem, the unilateral "rescue" flap technique as described by Rivera-Serrano et al. [53] preserves the posterior nasoseptal arterial pedicle on one side without obstructing access to the rostrum of the sphenoid, allowing for the elevation of a full nasoseptal flap, only if it becomes necessary.

Modifications of the posterior nasal artery-based nasoseptal flap have been recently described, including an anteriorly-based lateral nasal sidewall flap for anterior skull base defects, and a posteriorly-based nasoseptal wall flap for large transplanum defects [24•,52]. These flaps are a useful part of the rhinological and neurosurgeons' armamentarium to provide effective reconstructive options along the entire spectrum of sinonasal defects from the cribriform region in the anterior cranial fossa, to the sellar, parasellar, and clival regions. At our institution, we employ and have recently submitted a description of a bilateral nasoseptal vascular pedicle and olfactory epithelium preserving technique for use in the majority of sellar and parasellar defects where we do not anticipate a large CSF leak. In addition to preserving both vascular pedicles for future use, this also promotes rapid healing while reducing the incidence of postoperative epistaxis and olfactory dysfunction (Fig. 1).

Postoperative complications related to the sinonasal cavities in a large series of endonasal endoscopic approaches to sellar tumors most commonly include sinusitis (between 1.5 and 9.6\%), followed by epistaxis (1.09$4.3 \%$ ) [43]. Diminished olfactory function is a complication relevant to the endoscopic approach and has been shown to be as high as $50 \%$ in the immediate postoperative period, although modified techniques of reconstruction that avoid raising an entire nasoseptal flap have demonstrated somewhat reduced levels of olfactory impairment $[2,51,54,59]$.

\section{Pituitary Adenomas}

Pituitary adenomas are the third most common intracranial neoplasm in adults after gliomas and meningiomas, but represent the most frequent indication for a transsphenoidal operation with many if not most neurosurgeons today utilizing a fully endoscopic approach. Over the past year, a number of studies have been published further illustrating the advantages offered by endoscopy in comparison to the traditional speculum-based microscopic techniques.

Our group sought to examine the value of endoscopy for pituitary adenoma resection after initial removal using the operating microscope [48•]. In 140 patients who underwent maximal microscopic tumor resection, additional tumor was identified and removed as a result of endoscopic visualization in $36 \%$ of cases including $54 \%$ of patients with adenomas over $2 \mathrm{~cm}$. In patients with cavernous sinus invasion, additional tumor was removed using the endoscope in $57 \%$ of cases. Based on these findings, we concluded that the enhanced panoramic visualization and magnification of the endoscope appears to facilitate more complete tumor removal, and, taking into account a moderate learning curve, should eventually translate into higher remission rates for both endocrine-active and endocrineinactive adenomas.

Komotar et al. [40] compared the endoscopic and microscopic transsphenoidal approaches for giant pituitary 


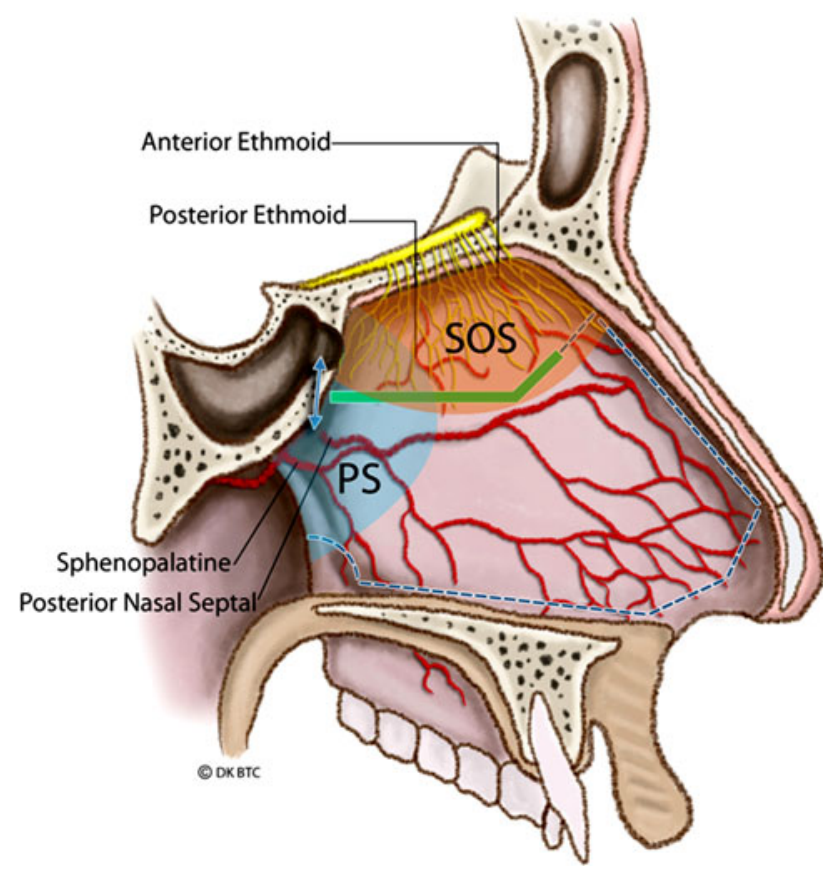

Fig. 1 Bilateral nasal mucosal incisional technique concept with preservation of sphenopalatine and posterior nasoseptal arteries along with the olfactory epithelium containing septal olfactory strip (SOS). The mucosal cuts are started several $\mathrm{mm}$ below the inferior aspect of the sphenoid ostia and carried anteriorly as shown by the green line. The dotted line shows mucosal cuts if a complete nasoseptal flap is needed. The double arrow denotes the typical 9-mm distance between the inferior edge of the ostium and posterior nasal septal artery. The blue shading indicates the extent of the posterior septectomy (PS) (Color figure online)

macroadenomas $(>4 \mathrm{~cm})$ utilizing a systematic literature review and found higher rates of gross total tumor resection and visual improvement in the endoscopic cohort, with a lower incidence of post-operative CSF leaks. Despite the overall improved visualization associated with endoscopy as compared to traditional microscopic transsphenoidal surgery, tumor regrowth and recurrence continue to occur at a moderate rate, and re-do operations make-up a significant portion of the total number of cases performed.

Cavallo et al. [10] recently published their findings utilizing an endoscopic transsphenoidal approach for recurrent or re-growing lesions. Over a 10-year period, approximately $9 \%$ of all pituitary adenoma surgeries were re-do procedures, with a gross total removal rate of $62.7 \%$. For recurrent functional adenomas, overall remission rate was lower at $33 \%$. An interesting finding which has often also been our experience is that the subgroup who had previously undergone a microsurgical transsphenoidal approach had a much higher gross total removal rate as compared to the group previously treated with an endoscopic approach (74 vs. $59 \%$ ). This is likely the result of a wider and more extensive sphenoidotomy having been performed with the utilization of the endoscope, as well as with a potentially larger amount of residual tumor being left with an initial microscopic approach that proved easier to visualize and remove with endoscopy.

In critically evaluating postoperative outcomes associated with the endonasal endoscopic removal of pituitary adenomas, Berker et al. [4••]. in their review of 624 cases. demonstrated the low number of complications which occur when the operation is performed by an experienced team of surgeons. Overall. they reported a rhinological complication rate of $1.3 \%$ including only 4 episodes of post-operative epistaxis, and also a low post-operative CSF leak rate of $1.3 \%$. They noted new anterior pituitary deficiency in $1.9 \%$ of patients and permanent post-operative diabetes insipidus (DI) in $0.4 \%$. In terms of catastrophic complications, they reported one case of an intraoperative internal carotid artery injury (ICA) occurring in a patient with Cushing's disease and an existing cavernous ICA aneurysm, and no mortalities directly related to the surgical procedure. Hofstetter et al. [26], in analyzing perioperative predictors of complications as well as extent of resection in macroadenomas, reported a similarly low complication rate. They determined that a tumor volume of greater than $10 \mathrm{~cm}^{3}$ and the presence of cavernous sinus invasion were both the strongest predictors of post-operative complications along with an inability to achieve gross total tumor resection. These findings reflect what we have previously reported on, that a large tumor diameter, especially when over $2 \mathrm{~cm}$, is the factor most associated with post-operative hypopituitarism [18]. In their recent article, however, they introduce a somewhat new concept concluding that total tumor volume rather than only tumor diameter was a more important predictive factor, and should therefore be utilized when necessary for macroadenomas as a better assessment of overall tumor size.

\section{Craniopharyngiomas}

Extended transsphenoidal approaches to craniopharyngiomas using the operating microscope primarily have previously been evaluated and compared to traditional transcranial routes [11, 31, 42, 46]. In many of these studies, the endoscope was often utilized only as an adjunct to the microscope in order to assist in tumor visualization [16]. However, limitations of the microscopic approach, including poor lateral tumor access, a long distance from the visualization source to the surgical target, loss of light with increased magnification, and the requirement of the nasal speculum even during the adjunctive use of the endoscope, have led many to adopt a purely endonasal endoscopic approach to these lesions [12, 22]. In addition, anatomic studies have often demonstrated the superior visualization of the suprasellar region achieved with the endoscope in comparison to the operating microscope [7]. 
Most recently, Leng et al. [44] analyzed the outcome of performing endoscopic endonasal resections of craniopharyngiomas in 26 cases. When the goal of surgery was gross total resection (GTR), this was achieved in $87 \%$ of newly diagnosed tumors and $83 \%$ of recurrent tumors. GTR or near total resection (NTR) was achieved in $95 \%$ of surgeries while visual improvement was noted to occur in $77 \%$ of patients. With regards to postoperative complications, new onset of anterior pituitary failure occurred in $38 \%$ of patients with $42 \%$ developing permanent post-operative DI. The reported CSF leak rate was $3.8 \%$.

Craniopharyngiomas extending superiorly into the third ventricle represent an important surgical challenge. Cavallo et al. [9] reported on their experience using an extended endonasal endoscopic approach on 12 patients harboring craniopharyngiomas arising from or extending to the third ventricle. They achieved a GTR rate of $66.7 \%$ and NTR in $25 \%$ of cases. Visual improvement occurred in $77.8 \%$ of patients and worsened in $16.7 \%$. New onset of DI was seen in $66.7 \%$ of patients, while two patients developed post-operative subdural hematomas. The authors specifically advocate considering this risk when the ventricular cavity is widely opened and there is associated pneumocephalus. The reported CSF leak rate of $16.7 \%$ was also somewhat higher than has been reported in previous extended endonasal endoscopic craniopharyngioma series, likely a result of the increased risk associated with entry into the third ventricle.

Finally, Komotar et al. [39・•] performed a meta-analysis to compare the endonasal endoscopic with the traditional microscopic and open techniques for craniopharyngioma removal using 88 studies published between 1995 and 2010. Overall, they found higher rates of both GTR (66.9 vs. $48.3 \%$ ) and improved visual outcome (56.2 vs. $33.1 \%)$ in the endoscopic cohorts. Other studies have shown similarly encouraging results using an extended endoscopic approach for craniopharyngiomas, establishing it as a legitimate and often preferable alternative to a transcranial procedure [8, 13, 19, 27]. Along with our own experience, these findings suggest that craniopharyngiomas of the sellar, suprasellar, and retrochiasmal space are ideally approached via an extended endonasal approach, while tumors with large lateral, anterior or suprachiasmatic extensions may be better accessed by a more traditional trans-cranial route. In addition, with the increasing use of stereotactic radiosurgery and stereotactic radiotherapy to treat residual craniopharyngiomas, patients might benefit from safe partial resection followed by observation or immediate post-operative radiation; if attempted, GTR may be associated with a higher risk of significant post-operative complications.
Meningiomas: Tuberculum sella, Planum Sphenoidale, and Olfactory Groove

Endonasal endoscopic access to meningiomas of the anterior cranial fossa including those of the olfactory groove, planum sphenoidale, and tuberculum sella are also being treated more frequently via an extended endoscopic endonasal approach. This trajectory is particularly appealing in that it allows for tumor resection without the need for brain retraction typically associated with open trans-cranial techniques [50]. In addition, this route allows for early devascularization of the meningeal blood supply. In previous reports, gross total or near total $(>95 \%)$ resection of anterior cranial fossa meningiomas was achieved in 83 $91 \%$ of patients treated via an extended endonasal endoscopic approach with no reported complications from excessive brain retraction or neurovascular manipulation $[14,15,21]$.

While the extended endonasal endoscopic route does provide direct access to meningiomas of the anterior skull base, anatomical restrictions for safe tumor removal include the posterior wall of the frontal sinus anteriorly, the cavernous and supraclinoid carotid arteries, and the optic nerves and mid-portion of the orbits laterally and the optic chiasm and pituitary infundibulum posteriorly. In order to determine the effect of these limitations on tumor removal, Komotar et al. [41] recently performed a meta-analysis comparing extended endoscopic approaches to traditional open trans-cranial procedures. Endoscopic removal was associated with a lower rate of GTR for all three types of meningiomas and a higher rate of post-operative CSF leaks. Visual outcomes were similar but there was a trend towards a reduction in overall postoperative complications in the endoscopic cohort. For example, in planum and tuberculum sella meningiomas, rates of GTR, postoperative visual improvement, postoperative CSF leak, and overall anosmia for open procedures were 84.1, 58.7, 4.3, and $13.8 \%$, respectively, while for endonasal endoscopic procedures, the numbers were $74.7,69.1,21.3$, and $5.3 \%$, indicating overall slightly worse outcomes in comparison. Based upon the current available data, therefore, the extended endonasal endoscopic approach is ideally indicated for smaller predominantly midline meningiomas that are typically $3 \mathrm{~cm}$ or less in maximal diameter [17].

\section{Schwannomas}

Non-vestibular schwannomas of the skull base are rare, with those arising from the trigeminal nerve being the most common. Normally originating from within Meckel's cave, these tumors are often large and dumbbell shaped with extension through the porus trigeminus into the posterior 
fossa. In addition, because tumors can grow along any of the three divisions of the trigeminal nerve, large components may also be found within the lateral wall of the cavernous sinus, the superior orbital fissure, the orbit, the pterygopalatine fossa, the maxillary sinus, and the infratemporal fossa [62]. Traditional trans-cranial approaches to these lesions, although effective, are often associated with excessive brain retraction while requiring the surgeon to traverse across critical neurovascular structures to gain access to the tumor. In addition utilizing a single approach to a tumor that has extended into multiple compartments is challenging, often resulting in some degree of temporary or permanent cranial nerve dysfunction along with postoperative problems with mastication, temporalis pain, and cosmetic disfigurement [63].

The extended endonasal endoscopic approach which utilizes an anteromedial rather than lateral corridor to trigeminal schwannomas arising from within Meckel's cave has previously been well described $[36,55]$. Overall, good results were reported primarily for tumors located medial to the trigeminal nerve and Gasserian ganglion, or in patients with lateral tumors and minimal nerve function pre-operatively. Most recently, Zhang et al. [63] described their results on 8 patients harboring trigeminal schwannomas with extracranial extension to the infratemporal fossa. All patients were treated using a purely endonasal endoscopic transmaxillary transpterygoid approach. They reported excellent exposure and visualization of both the lesion and the surrounding neurovascular structures, and in each case GTR was achieved with no significant postoperative complications. Komatzu et al. [38] also demonstrated similar findings in a series of cadaveric dissections reinforcing the enhanced visualization of Meckel's cave, V2, and the infratemporal fossa which can be obtained via an endonasal endoscopic approach. Overall, the use of an endonasal corridor provides a minimally invasive, safe alternative for accessing non-vestibular schwannomas and should be utilized when necessary for favorable lesions with minimal lateral extension.

\section{Pituitary Centers of Excellence and Residency/ Fellowship Training}

The utilization of endonasal endoscopic approaches for skull base tumors requires specialized practitioners optimally trained in the surgical technique as well as in the preand postoperative management of these patients. In the future, as technology allows us to continue to push the envelope further in endonasal endoscopic surgery, we recognize the importance of establishing standard training guidelines for neurosurgeons and otolaryngologists along with a verification process identifying centers which contain highly specialized practitioners who are experienced in the multi-disciplinary treatment of the full array of pituitary tumors and related brain tumors involving the ventral skull base. In a recently published paper focused on pituitary tumors, we suggest criteria and guidelines for establishing so-called "pituitary centers of excellence" which should provide: (1) comprehensive care and support to patients with pituitary disorders; (2) residency training, fellowship training, and/or continuing medical education in the management of pituitary and neuroendocrine disease; and (3) contribute to research in pituitary disorders [47]. It is our belief that, by establishing an accepted recognition and verification process for these institutions, patient management would be significantly improved. More than anything, it would allow those patients with complex disorders of the pituitary to be able to better identify where they are likely to receive optimal care with the latest evidence-based treatments. In addition, the collaboration of highly trained practitioners from different modalities provides the optimum environment for residency and fellowship instruction as well as cutting edge research.

With regards to surgical training, the idea of utilizing a modular incremental teaching program in order to reduce the risk of complications during surgeon development has previously been described [57]. Most recently, as resident hours continue to be restricted, thereby reducing the number of operative cases during training, the utilization of cadaveric dissection, implantable reproducible tumor models and psychomotor skill training devices have been described in order to shorten the learning curve in endonasal endoscopic surgery $[3,25,60]$. Ultimately, however, larger case volumes in combination with high-level instruction in endoscopy represent the most important factors in producing future well-trained skull base surgeons [56].

\section{Conclusion}

Over the last decade, the endonasal endoscopic approach has gradually become an established skull base operative technique for the removal of most benign sellar and parasellar tumors, including pituitary adenomas, RCCs, craniopharyngiomas, midline meningiomas, and schwannomas. With enhanced high-definition visualization, improved instrumentation, and more reliable skull base closure techniques, as well as growing worldwide experience, surgical outcomes and complication rates continue to improve. Further advances and wider acceptance will likely continue, but neurosurgeons with limited experience should apply this approach in an incremental fashion commensurate with their anatomical knowledge, surgical experience, and available technology. Partnering with an otolaryngologist experienced 
in sino-nasal endoscopy is considered critical in developing a full multi-disciplinary team including endocrinologists, neuro-ophthalmologists, radiation oncologists, and medical oncologists. This team approach is essential to carefully define surgical goals and approach, to maximize chances of operative success and complication avoidance, and to provide comprehensive postoperative follow-up.

Acknowledgments We would like to acknowledge support of this research from the following individuals: Carole Zumbro and George Adler family; Carole and Jeff Schwartz; Ruth K. March and family.

\section{Compliance with Ethics Guidelines}

Conflict of Interest Daniel F. Kelly receives royalties from Mizuho, Inc. Aaron R. Cutler, Kian Karimi, Pablo Villanueva, Garni Barkhoudarian, and Chester F Griffiths declare that they have no conflict of interest.

Human and Animal Rights and Informed Consent This article does not contain any studies with human or animal subjects performed by any of the authors.

\section{References}

Papers of particular interest, published recently, have been highlighted as:

- Of importance

-• Of major importance

1. Adappa ND, Learned KO, Palmer JN, Newman JG, Lee JY. Radiographic enhancement of the nasoseptal flap does not predict postoperative cerebrospinal fluid leaks in endoscopic skull base reconstruction. Laryngoscope. 2012;122(6):1226-34.

2. Alobid I, Ensenat J, Marino-Sanchez F, de Notaris M, Centellas $\mathrm{S}$, Mullo $\mathrm{J}$, et al. Impairment in olfaction and mucociliary clearance after expanded endonasal approach using vascularized septal flap reconstruction for skull base tumors. Neurosurgery. 2013;72(4):540-6.

3. Berhouma M, Baidya NB, Ismail AA, Zhang J, Ammirati M. Shortening the learning curve in endoscopic endonasal skull base surgery: a reproducible polymer tumor model for the trans-sphenoidal trans-tubercular approach to retro-infundibular tumors. Clin Neurol Neurosurg. 2013;. doi:10.1016/j.clineuro.2013.02.013.

4. •- Berker M, Hazer DB, Yucel T, Gurlek A, Cila A, Aldur M, et al. Complications of endoscopic surgery of the pituitary adenomas: analysis of 570 patients and review of the literature. Pituitary 2012;15:288-300. Large case series demonstrating low complication rate associated with endoscopic endonasal approach for pituitary adenomas when performed by experienced teams.

5. Cappabianca P, Cavallo LM, Colao A. Endoscopic endonasal transsphenoidal approach: outcome analysis of 100 consecutive patients. Minim Invasive Neurosurg. 2002;45:193-200.

6. Cappabianca P, Frank G, Pasquini E, de Divitiis O, Calbucci F. Extended endoscopic endonasal transsphenoidal approaches to the suprasellar region, planum sphenoidale and clivus. In: de Divitiis E, Cappabianca P, editors. Endoscopic endonasal transsphenoidal surgery. Vienna: Springer; 2003. p. 176-87.

7. Catapano D, Sloffer CA, Frank G, Pasquini E, D'Angelo VA, Lanzino G. Comparison between the microscope and endoscope in the direct endonasal extended transsphenoidal approach: anatomical study. J Neurosurg. 2006;104(3):419-25.

8. Cavallo LM, Prevedello DM, Solari D, Gardner PA, Esposito F, Snyderman $\mathrm{CH}$, et al. Extended endoscopic endonasal transsphenoidal approach for residual or recurrent craniopharyngiomas. J Neurosurg. 2009;111:578-89.

9. Cavallo LM, Solari D, Esposito F, Cappabianca P. The endoscopic endonasal approach for the management of craniopharyngiomas involving the third ventricle. Neurosur Rev. 2013;36:27-38.

10. Cavallo LM, Solari D, Tasiou A, Esposito F, de Angelis M, D'Enza AI, et al. Endoscopic endonasal transsphenoidal removal of recurrent and regrowing pituitary adenomas: experience on a 59-patient series. World Neurosurg. 2012;. doi:10.1016/j.wneu. 2012.10.008.

11. Chakrabarti I, Amar AP, Couldwell W, Weiss MH. Long-term neurological, visual, and endocrine outcomes following transnasal resection of craniopharyngioma. J Neurosurg. 2005;102:6507.

12. Couldwell WT, Weiss MH, Rabb C, Liu JK, Apfelbaum RI, Fukushima T. Variations on the standard transsphenoidal approach to the sellar region, with emphasis on the extended approaches and parasellar approaches: surgical experience in 105 cases. Neurosurgery. 2004;55:539-50.

13. de Divitiis E, Cappabianca P, Cavallo LM, Esposito F, de Divitiis $\mathrm{O}$, Messina A. Extended endoscopic transsphenoidal approach for extrasellar craniopharyngiomas. Neurosurgery. 2007;61(5 Suppl 2):219-28.

14. de Divitiis E, Esposito F, Cappabianca P, Cavallo LM, de Divitiis O. Tuberculum sellae meningiomas: high route or low route? A series of 51 consecutive cases. Neurosurgery. 2008;62(3):556-63.

15. de Divitiis E, Esposito F, Cappabianca P, Cavallo LM, de Divitiis O, Esposito I. Endoscopic transnasal resection of anterior cranial fossa meningiomas. Neurosurg Focus. 2008;25(6):E8.

16. Dusick JR, Esposito F, Kelly DF, Cohan P, DeSalles A, Becker $\mathrm{DP}$, et al. The extended direct endonasal transsphenoidal approach for nonadenomatous suprasellar tumors. J Neurosurg. 2005;102:832-41.

17. Fatemi N, Dusick JR, De Paiva Neto MA, Malkasian D, Kelly DF. Endonasal versus supraorbital keyhole removal of craniopharyngiomas and tuberculum sellae meningiomas. Neurosurgery. 2009;64(5 Suppl 2):269-86.

18. Fatemi N, Dusick JR, Mattozo C, McArthur DL, Cohan P, Boscardin J, et al. Pituitary hormonal loss and recovery after transsphenoidal adenoma removal. Neurosurgery. 2008;63:70919.

19. Frank G, Pasquini E, Doglietto F, Mazzatenta D, Sciarretta V, Farneti G, et al. The endoscopic extended transsphenoidal approach for craniopharyngiomas. Neurosurgery. 2006;59(Suppl 1):ONS75-83.

20. Gandhi CD, Christiano LD, Eloy JA, Prestigiacomo CJ, Post KD. The historical evolution of transsphenoidal surgery: facilitation by technological advances. Neurosurg Focus. 2009;27(3):E8.

21. Gardner PA, Kassam AB, Thomas A, Snyderman CH, Carrau RL, Mintz $\mathrm{AH}$, et al. Endoscopic endonasal resection of anterior cranial base meningiomas. Neurosurgery. 2008;63(1):36-54.

22. Gardner PA, Prevedello DM, Kassam AB, Snyderman CH, Carrau RL, Mintz AH. The evolution of the endonasal approach for craniopharyngiomas. J Neurosurg. 2008;108(5):1043-7.

23. Hadad G, Bassagaisteguy L, Carrau RL, Mataza JC, Kassam A, Snyderman $\mathrm{CH}$, et al. A novel reconstructive technique after endoscopic expanded endonasal approaches: vascular pedicle nasoseptal flap. Laryngoscope. 2006;116(10):1882-6.

24. • Hadad G, Rivera-Serrano CM, Bassagaisteguy LH, Carrau RL, Fernandez-Miranda J, Prevedello DM, et al. Anterior pedicle lateral nasal wall flap: a novel technique for the reconstruction of 
anterior skull base defects. Laryngoscope 2011;121 Suppl 8:1606-10. Provides description of a reliable alternative to posteriorly-based nasoseptal flap for use in anterior skull base defects.

25. Hirayama R, Fujimoto Y, Umegaki M, Kagawa N, Kinoshita M, Hashimoto N, et al. Training to acquire psychomotor skills for endoscopic endonasal surgery using a personal webcam trainer. $\mathrm{J}$ Neurosurg. 2013;. doi:10.3171/2012.12.JNS12908.

26. Hofstetter CP, Nanaszko MJ, Mubita LL, Tsiouris J, Anand VK, Schwartz TH. Volumetric classification of pituitary macroadenomas predicts outcome and morbidity following endoscopic endonasal transsphenoidal surgery. Pituitary. 2012;15:450-63.

27. Jane JA Jr, Kiehna E, Payne SC, Early SV, Laws ER Jr. Early outcomes of endoscopic transsphenoidal surgery for adult craniopharyngiomas. Neurosurg Focus. 2010;28(4):E9.

28. Jho HD, Carrau RL. Endoscopic endonasal transsphenoidal surgery: experience with 50 patients. J Neurosurg. 1997;87:44-51.

29. Jho HD, Ha HG. Endoscopic endonasal skull base surgery: part 1 -the midline anterior fossa skull base. Minim Invasive Neurosurg. 2004;47:1-8.

30. Jho HD, Ha HG. Endoscopic endonasal skull base surgery: part 3 - the clivus and posterior fossa. Minim Invasive Neurosurg. 2004;47:16-23.

31. Kaptain GJ, Vincent DA, Sheehan JP, Laws ER Jr. Transsphenoidal approaches for the extracapsular resection of midline suprasellar and anterior cranial base lesions. Neurosurgery. 2001;49:94-101.

32. Kassam A, Snyderman C, Gardner P, Carrau R, Spiro R. The expanded endonasal approach: a fully endoscopic transnasal approach and resection of the odontoid process: technical case report. Neurosurgery. 2005;57(Suppl 1):E213.

33. Kassam A, Snyderman CH, Mintz A, Gardner P, Carrau RL. Expanded endonasal approach: the rostrocaudal axis. Part I. Crista galli to the sella turcica. Neurosurg Focus. 2005;19(1):E3.

34. Kassam A, Snyderman CH, Mintz A, Gardner P, Carrau RL. Expanded endonasal approach: the rostrocaudal axis. Part II. Posterior clinoids to the foramen magnum. Neurosurg Focus. 2005;19(1):E4.

35. Kassam AB, Gardner P, Snyderman C, Mintz A, Carrau R. Expanded endonasal approach: fully endoscopic, completely transnasal approach to the middle third of the clivus, petrous bone, middle cranial fossa, and infratemporal fossa. Neurosurg Focus. 2005;19(1):E6.

36. Kassam AB, Prevedello DM, Carrau RL, Snyderman CH, Gardner P, Osawa S, et al. The front door to meckel's cave: an anteromedial corridor via expanded endoscopic endonasal approach- technical considerations and clinical series. Neurosurgery. 2009;64(Suppl 3):71-83.

37. Kassam AB, Thomas A, Carrau RL, Snyderman CH, Vescan A, Prevedello D, et al. Endoscopic reconstruction of the cranial base using a pedicled nasoseptal flap. Neurosurgery. 2008;63:ONS4453.

38. Komatsu F, Komatsu M, Di leva A, Tschabitscher M. Endoscopic approaches to the trigeminal nerve and clinical consideration for trigeminal schwannomas: a cadaveric study. J Neurosurgery. 2012;117(4):690-6.

39. •• Komotar RJ, Starke RM, Raper DM, Anand VK, Schwartz TH. Endoscopic endonasal compared with microscopic transsphenoidal and open transcranial resection of craniopharyngiomas. World Neurosurg 2012;77(2):329-41. Large meta-analysis demonstrating improved rate of gross total resection and visual outcome when endoscopic endonasal approach is utilized for craniopharyngiomas as compared to microscopic transsphenoidal or open transcranial techniques.

40. Komotar RJ, Starke RM, Raper DM, Anand VK, Schwartz TH. Endoscopic endonasal compared with microscopic transsphenoidal and open transcranial resection of giant pitutary adenomas. Pituitary. 2012;15(2):150-9.

41. Komotar RJ, Starke RM, Raper DM, Anand VK, Schwartz TH. Endoscopic endonasal versus open transcranial resection of anterior midline skull base meningiomas. World Neurosurg. 2012;77(5-6):713-24.

42. Kouri JG, Chen MY, Watson JC, Oldfield EH. Resection of suprasellar tumors by using a modified transsphenoidal approach. Report of four cases. J Neurosurg. 2000;92:1028-35.

43. Kumar S, Darr A, Hobbs CG, Carlin WV. Endoscopic, endonasal, trans-sphenoidal hypophysectomy: retrospective analysis of 171 procedures. J Laryngol Otol. 2012;126(10):1033-40.

44. Leng Z, Greenfield J, Souweidane M, Anand VK, Schwartz TH. Endoscopic endonasal resection of craniopharyngiomas: analysis of outcome including extent of resection, cerebrospinal fluid leak, return to preoperative productivity, and body mass index. Neurosurgery. 2012;70:110-24.

45. Liu JK, Das K, Weiss MH, Laws ER Jr, Couldwell WT. The history and evolution of transsphenoidal surgery. J Neurosurg. 2001;95(6):1083-96.

46. Maira G, Anile C, Rossi GF, Colosimo C. Surgical treatment of craniopharyngiomas: an evaluation of the transsphenoidal and pterional approaches. Neurosurgery. 1995;36:715-24.

47. McLaughlin N, Laws ER, Oyesiku NM, Katznelson L, Kelly DF. Pituitary centers of excellence. Neurosurgery. 2012;71(5):916-26.

48. - McLaughlin N, Eisenberg AA, Cohan P, Chaloner CB, Kelly DF. Value of endoscopy for maximizing tumor removal in endonasal transsphenoidal pituitary adenoma surgery. J Neurosurg 2013;118(3):613-20. In a series of 140 patients, after maximal tumor removal using a microscope, the authors demonstrated additional adenoma removal in 36\% of cases; for tumors $2 \mathrm{~cm}$ or greater in maximal diameter, additional tumor removal was achieved in $54 \%$.

49. Morera VA, Fernandez-Miranda JC, Prevedello DM, Madhok R, Barges-Coll J, Gardner P, et al. "Far-medial" expanded endonasal approach to the inferior third of the clivus: the transcondylar and transjugular tubercle approaches. Neurosurgery. 2010;66(6 Suppl Operative):211-20.

50. Prevedello DM, Doglietto F, Jane JA Jr, Jagannathan J, Han J, Laws ER Jr. History of endoscopic skull base surgery: its evolution and current reality. J Neurosurg. 2007;107:206-13.

51. Rawal RB, Kimple AJ, Dugar DR, Zanation AM. Minimizing morbidity in endoscopic pituitary surgery: outcomes of the novel nasoseptal rescue flap technique. Otolaryngol Head Neck Surg. 2012;147(3):434-7.

52. Rivera-Serrano CM, Bassagaisteguy LH, Hadad G, Carrau RL, Kelly D, Prevedello DM, et al. Posterior pedicle lateral nasal wall flap: new reconstructive technique for large defects of the skull base. Am J Rhinol Allergy. 2011;25:e212-6.

53. Rivera-Serrano CM, Snyderman CH, Gardner P, Prevedello D, Wheless S, Kassam AB, et al. Nasoseptal "rescue" flap: a novel modification of the nasoseptal flap technique for pituitary surgery. Laryngoscope. 2011;121(5):990-3.

54. Rotenberg BW, Saunders S, Duggal H. Olfactory outcomes after endoscopic transsphenoidal pituitary surgery. Laryngoscope. 2011;121(8):1611-3.

55. Shin SS, Gardner PA, Stefko ST, Madhok R, Fernandez-Miranda $\mathrm{J}$, Snyderman $\mathrm{CH}$. Endoscopic endonasal approach for nonvestibular schwannomas. Neurosurgery. 2011;69:1046-57.

56. Snyderman CH, Fernandez-Miranda J, Gardner PA. Training in neurorhinology: the impact of case volume on the learning curve. Otolaryngol Clin North Am. 2011;44(5):1223-8.

57. Snyderman CH, Kassam AB, Carrau RL, Mintz A, Gardner PA, Prevedello DM. Acquisition of surgical skills for endonasal skull base surgery: a training program. Laryngoscope. 2007;117(4):699-705. 
58. Spencer WR, Das K, Nwagu C, Wenk E, Schaefer SD, Moscatello A, et al. Approaches to the sellar and parasellar region: anatomic comparison of the microscope versus endoscope. Laryngoscope. 1999;109:791-4.

59. Tam S, Duggal N, Rotenberg BW. Olfactory outcomes following endoscopic pituitary surgery with or without septal flap reconstruction: a randomized controlled trial. Int Forum Allergy Rhinol. 2012;. doi:10.1002/alr.21069.

60. Tschabitscher M, Di Ieva A. Practical guidelines for setting up an endoscopic/skull base cadaver laboratory. World Neurosurg. 2013;. doi:10.1016/j.wneu.2011.
61. Weiss M. Transnasal transsphenoidal approach. In: Apuzzo ML, editor. Surgery of the third ventricle. Baltimore: Williams \& Wilkins; 1987. p. 476-94.

62. Youssef S, Kim E-Y, Aziz KMA, Hemida S, Keller JT, van Loveren HR. The subtemporal interdural approach to dumbbellshaped trigeminal schwannomas: cadaveric prosection. Neurosurgery. 2006;59(ONS Suppl 4):270-8.

63. Zhang Q, Feng K, Ge C, Hongchuan G, Mingchu L. Endoscopic endonasal management of trigeminal schwannomas extending into the infratemporal fossa. J Clin Neurosci. 2012;19:862-5. 